\title{
G
} DE GRUYTER
OPEN

DOI: $10.1515 /$ plass-2017-0004

Dorota Sołtys-Kalina

Plant Breeding and Acclimatization Institute - National Research Institute Młochów Research Center, 05-831 Młochów, Platanowa Str., 19, Poland, e-mail: d.soltys@ihar.edu.pl

\section{ASSESSMENT OF PHYTOTOXIC POTENTIAL OF POTATO GENOTYPES}

\begin{abstract}
In the laboratory studies on allelopathy, phytotoxicity is defined as a negative impact of plant's extracts or natural compounds derived from plants, on germination and/or growth of the tested (acceptor) plant. Glycoalkaloids are the main biologically active compounds of the potato and are involved in potato phytotoxicity (the correlation coefficient of the length of the test plant with the concentration of total glycoalkaloids present in the leaf extracts of forty potato genotypes was $r=-0.41$ ). The assessment of phytotoxic abilities of the potato is a two-step procedure which consists of determining glycoalkaloids in potato leaf extracts and analyzing the root and hypocotyl lengths of the test plant growing in potato leaf extracts.
\end{abstract}

Keywords: allelopathy, glycoalkaloids (TGA), leaf extracts, mustard, test plant

\section{INTRODUCTION}

Glycoalkaloids are very important bioactive compounds in the potato plant. They take part in constitutive defense against microorganisms and herbivores. The basic glycoalkaloids recognized in the potato are $\alpha$-solanine and $\alpha$ chaconine, often described as "total glycoalkaloids" (TGA). In the cultivated potato, the content of TGA in tubers is strictly controlled and cannot exceed $200 \mathrm{mg} \times \mathrm{kg}^{-1}$ of fresh weight (table potato cultivars should not contain more than $100 \mathrm{mg} \times \mathrm{kg}^{-1}$ of TGA) due to negative effects on human health (Friedman, 2006). In potato leaves, the content of TGA can be higher than in tubers. However, an increase in the TGA content in tubers entails an increase in the TGA concentration in leaves $(r=0.865)$ (Uppal, 1987).

Communicated by Ewa Zimnoch-Guzowska 
During the growing season, glycoalkaloids continuously leach from potato stems (leaves are the main source of TGA) into the soil. After harvest, glycoalkaloids are freed to the soil from the necrotic biomass and the tubers left in the field (about $0.1-0.5 \mathrm{~kg} \mathrm{~m}^{-2}$ tubers remain in the soil) (Jensen et al., 2007). Glycoalkaloids present in the soil are involved in allelopathic interactions between potato plant and microorganisms, next-season crops or weeds. The ability of a plant to inhibit seed germination or seedling growth of the neighboring plants is defined as allelopathic potential.

The allelopathic properties can facilitate the potato plants to be more competitive against weeds appearing in the field and microorganisms evoking soilborne diseases. When the phenomenon of allelopathy is studied under controlled laboratory conditions, it is called "phytotoxicity" (Soltys et al., 2012). Assessing the phytotoxic potential of potato genotypes requires determining the TGA content in potato leaf extracts and the growth of seedlings of the test plant. Potato genotypes, that inhibit test plant growth in comparison to control plants growing in water, are phytotoxic. However, the strength of phytotoxic potential may fluctuate throughout the years. In our study, in the set of 40 genotypes of the potato, including cultivars, wild species and diploid potato hybrids, the average length of seedling of the test plants per genotype was negatively correlated with glycoalkaloids concentration in potato leaf extracts $(r=-0.41)$. A high TGA content in potato leaf extracts corresponded to a high phytotoxic potential. It means that potato plant extracts inhibit the growth of test plant seedlings by $30 \%$ or more, and have $25 \mu \mathrm{g} \times \mathrm{ml}^{-1}$ or more of TGA in leaf extracts (SoltysKalina, unpublished data). Analysis of TGA concentration in potato leaf extracts is to be done by a modified method by Andreu et al. (2001).

\section{MATERIALS AND REAGENTS}

1) Mortal pestle, porcelain (Carl Roth, cat. No 1567.1)

2) Petri dishes, circle (Carl Roth, cat. No EL49.1)

3) Petri dishes, square (Carl Roth, cat. No PX67.1)

4) Cellulose filters Rotilabo ${ }^{\circledR}$ (Carl Roth, cat. No XP10.1)

5) Reaction tubes $50 \mathrm{ml}, 15 \mathrm{ml}$ (Sarstedt, cat. No 62.547.254; cat. No 62.554.502)

6) Filter paper Rotilabo® (Carl Roth, cat. No XP43.1)

7) Laboratory funnel Rotilabo® (Carl Roth, cat. No HY47.1)

8) Acetic acid (Sigma-Aldrich, cat. No A6283-1L)

9) $5 \mathrm{M}$ ammonium hydroxide (Honeywell Fluka ${ }^{\mathrm{TM}}$, cat. No 60-023-92)

10) Methanol (POCH, cat. No 621990110)

11) Sulphuric acid (Sigma-Aldrich, cat. No 258105)

12) Paraformaldehyde (Sigma-Aldrich, cat. No 47608)

13) Alpha-solanine (Sigma-Aldrich, cat. No S3757)

14) Sodium hypochlorite (POCH, cat. No 806722992)

15) Liquid nitrogen

16) Distilled water 
1) Pipette kit PM 200, PM 1000, PM 5000 (Gilson PIPETMAN $\AA$, cat. No F132601; cat. No F123602; cat. No F123603)

2) Vacuum rotary evaporator

3) Centrifuge Heraeus ${ }^{\mathrm{TM}}$ Multifuge ${ }^{\mathrm{TM}} \mathrm{X} 3$ Centrifuge Series (Thermo Fisher, cat. No 75004500$)$

4) Water bath (IKA, cat. No 0020009381)

5) Laboratory cradle (Benchmark, cat. No BR2000-E)

6) Spectrophotometer Hitachi U-1900

7) Growing chamber (dark)

8) Phytotron

PROCEDURE

\section{Preparation of potato leaf extracts}

1) Potato leaves are used as a source of phytotoxic extracts. Leaflets of expanded potato leaves (from the middle part of the stem) from at least three potato plants in the middle of the flowering period. The collected leaves are mixed, portioned into $0.5 \mathrm{~g}$ samples and frozen in liquid nitrogen until use.

2) Leaf samples (at least three samples per genotype) are ground in liquid nitrogen and transferred into $50 \mathrm{ml}$ tubes, and mixed with $50 \mathrm{ml}$ of distilled water. Afterwards, the tubes are put into a laboratory cradle at $20^{\circ} \mathrm{C}$ in the dark for $24 \mathrm{~h}$. Then, the extracts are centrifuge at 5,000 $\times \mathrm{g}$ for 10 min and filtered gravitationally using filter paper.

\section{Assessment of TGA concentration in potato leaf extracts}

1) Concentrate potato leaf extracts (from each of the three samples) 4-fold in a vacuum rotary evaporator.

2) Transfer $2 \mathrm{ml}$ of the concentrated extracts (at least 2 repetitions per sample) into $15 \mathrm{ml}$ tubes, then add $5 \mathrm{ml}$ of $10 \%$ acetic acid.

3) Centrifuge the samples at $5,000 \times \mathrm{g}$ at $10^{\circ} \mathrm{C}$ for $30 \mathrm{~min}$.

4) Transfer the supernatant into new $15 \mathrm{ml}$ tubes.

5) Adjust $\mathrm{pH}$ to 10.0 using $5 \mathrm{M}$ ammonium hydroxide (add approximately of $3.6 \mathrm{ml}$ ).

6) Incubate the samples in a water bath $\left(80^{\circ} \mathrm{C}\right)$ for $30 \mathrm{~min}$, then transfer to $4^{\circ} \mathrm{C}$ for $2.5 \mathrm{~h}$. The last $30 \mathrm{~min}$ in $-20^{\circ} \mathrm{C}$.

7) After the incubation centrifuge the samples at $5,000 \times \mathrm{g}$, at $10^{\circ} \mathrm{C}$ for 30 min.

8) Remove the supernatant and dissolve the pellet in $330 \mu \mathrm{l}$ of $100 \%$ methanol, transfer onto ice.

9) Add $660 \mu 1$ of $98 \%$ sulphuric acid and $330 \mu 1$ of $1 \%$ paraformaldehyde. 
10) Incubate the samples at room temperature for $90 \mathrm{~min}$.

11) Read absorbance spectrophotometrically at $562 \mathrm{~nm}$ against a blank sample containing $330 \mu \mathrm{l}$ of $100 \%$ methanol, $660 \mu 1$ of $98 \%$ sulphuric acid and $330 \mu \mathrm{l}$ of $1 \%$ paraformaldehyde.

\section{Plotting the standard curve}

The concentration of glycoalkaloids is evaluated from the standard curve. For this purpose, prepare $\alpha$-solanine standard solutions in $100 \%$ methanol at the concentration of $10,20,40,80$ and $160 \mu \mathrm{g} \mathrm{ml}^{-1}$. Take $330 \mu \mathrm{l}$ of the standard solution, add $660 \mu \mathrm{l}$ of $98 \%$ sulphuric acid and $330 \mu \mathrm{l}$ of $1 \%$ paraformaldehyde, incubate at room temperature for $90 \mathrm{~min}$. Measure the absorbance spectrophotometrically at wavelength $562 \mathrm{~nm}$ against the blank sample. Interpolate the concentrations of glycoalkaloids in samples from step 11 from the curve (Fig. 1) and expressed as an equivalents of $\alpha$-solanine.

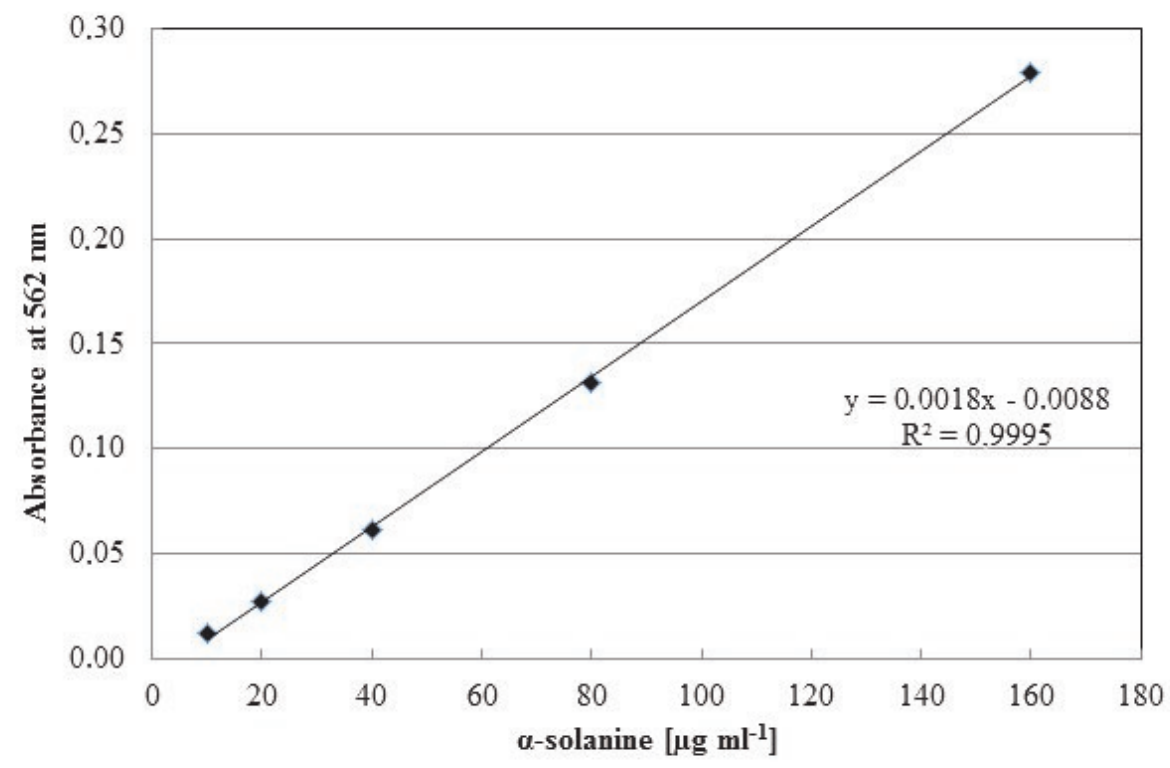

Fig. 1. The standard curve of $\alpha$-solanine concentration. Standard curve is prepared using $\alpha$-solanine solutions.

Determination of the length of test plant seedlings growing in extract of potato leaves

1) Use mustard (Sinapis alba L.) cv. Rota as the acceptor plant.

2) Sterilize mustard seeds in $5 \%$ sodium hypochlorite for $5 \mathrm{~min}$.

3 ) Sow the mustard seeds on Petri dishes (ø 18) filled with filter paper soaked with $15 \mathrm{ml}$ of distilled water and incubate the seeds in the dark at $20^{\circ} \mathrm{C}$ for $18 \mathrm{~h}$. 
4) Fill new Petri dishes (square, $12 \mathrm{~cm}$ side) with filter paper and soak with $6 \mathrm{ml}$ distilled water (control) or potato leaf extracts. Transfer the mustard seedlings of equal size (the root of approx. $3 \mathrm{~mm}$ length) onto dishes, 15 seedlings per dish. Cover the seedlings with an additional layer of filter paper and set vertically, so that the root grows under the action of gravity.

5) Incubate in the dark at $20^{\circ} \mathrm{C}$ for 5 days.

6) Measure the length of root and hypocotyl.

7) Compare the length of the control seedlings (growing in water) with those growing in the potato leaf extracts (Photo 1). The potato genotypes that inhibited the growth of mustard seedlings to a statistically significant degree, when compared to control, are phytotoxic.

The assessment of phytotoxic potential of potato requires controlled growth conditions. That is why plants should be planted in growing chamber/phytotron. To select potato genotypes of stable phytotoxic potential (repeatable in years), it is necessary to compare the tested genotypes to those characterized by high phytotoxic potential with high TGA concentration in potato leaf extracts.

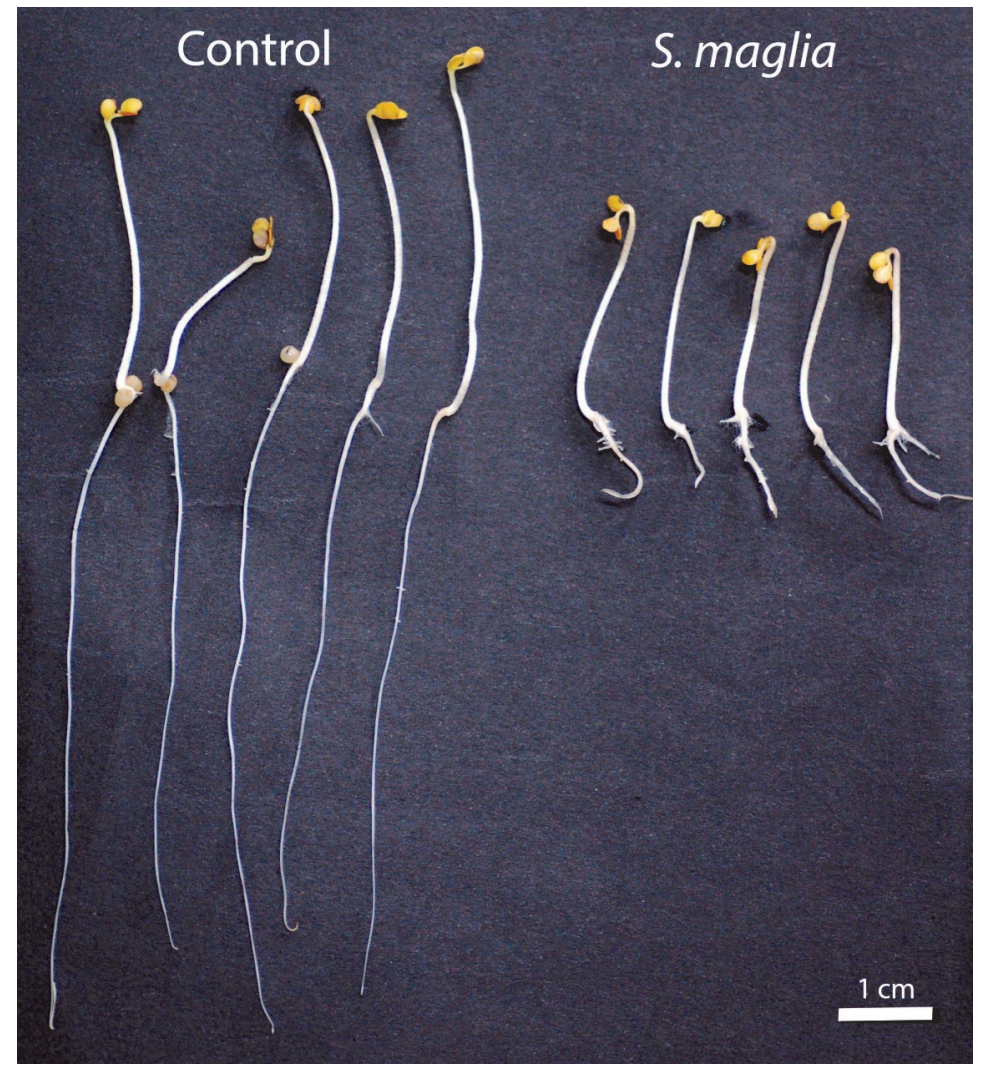

Photo 1. Mustard seedlings growing 5 days in water (control) or in the leaf extract of the wild potato species Solanum maglia. 


\section{ACKNOWLEDGMENTS}

This work has been done in frame of the Statutory Project of the Plant Breeding and Acclimatization Institute - National Research Institute number 1-3-00-1-01.

\section{REFERENCES}

Andreu A., Oliva C., Distel S., Daleo G. 2001. Production of phytoalexins, glycoalkaloids and phenolics in leaves and tubers of potato cultivars with different degrees of field resistance after infection with $P h y$ tophthora infestans. Potato Res. 44: 1-9.

Friedman M. 2006. Potato Glycoalkaloids and metabolites: role in the plant and in the diet. J. of Agr. Food Chem. 54:8655-8681.

Jensen P.H., Harder B. J., Strobel B.W., Svensmark B., Hansen H. C. B. 2007. Extraction and determination of the potato glycoalkaloid $\alpha$-solanine in soil. Int. J. Environ. An. Chem. 87: 813-824.

Soltys D., Rudzińska-Langwald A., Gniazdowska A., Wiśniewska A., Bogatek R. 2012. Inhibition of tomato (Solanum lycopersicum L.) root growth by cyanamide is due to altered cell division, phytohormone balance and expansin gene expression. Planta 236: 1625-1638.

Uppal D.S. 1987. Varietal and environmental effect on the glycoalkaloids content of potato (Solanum tuberosum L.). Plant Foods for Hum. Nutr. 37: 333-340. 